\title{
Decompressive laminectomy with instrumented posterolateral fusion for degenerative lumbar disease in elderly, is it safe and beneficial?
}

\author{
Ahmed A. Arab*i(D), Mohammed H. Eltantawy and Ashraf El-Desouky
}

\begin{abstract}
Background: With improvement of health care in last decades, the age of general population increased. As the elderly with degenerative lumbar disease needs to remain physically active for more years, lumbar decompression surgery with instrumented fusion is further considered and is gaining wide acceptance as it provides good results with relative minimal risk. This study aim to evaluate the safety and efficacy of lumbar decompression with instrumented fusion in elderly
\end{abstract}

Results: This is a prospective non-randomized clinical study conducted from July 2014 to July 2019. The included patients had chronic low back pain, radiculopathy, and/or neurogenic claudication due to degenerative lumbar disease with failed conservative management. They underwent lumbar decompression with instrumented posterolateral fusion. All patients were at least 55 years old at time of surgery and were clinically assessed as regard perioperative risk and morbidity, besides assessment of pre- and postoperative visual analog score (VAS) and Oswestry Disability Index (ODI). Data was collected and analyzed. Thirty-five patients were included in this study with mean age of 63 years. All patients presented with back pain, $77.1 \%$ with radiculopathy, and $60 \%$ with neurogenic claudication. Preoperative comorbidity was present in $60 \%$ of cases, where hypertension, diabetes, and cardiac troubles were $31.4 \%, 31.4 \%$, and $14.3 \%$ respectively. The average operated level was 3.1. The complication rate was $11.4 \%$ with 2 cases with dural tear (5.7\%), 2 cases with CSF leakage (5.7\%), 1 case with wound seroma (2.8\%), and 1 case with wound infection. Postoperative new comorbidity occurred in 5 cases (14.3\%). Visual analog score (VAS) and Oswestry disability index (ODI) were recorded preoperatively and 18 months postoperatively; as regards pain, VAS improved significantly from $7.8 \pm 0.87$ to $1.8 \pm 1.04$ ( $P$ value $<0.00001$ ), and ODI improved significantly from $58.1 \pm 11$ to $17.5 \pm 8.3$ ( $P$ value $<0.00001$ )

Conclusion: Lumbar decompression surgery with posterolateral instrumented fusion is a safe and effective surgery in elderly, as it provides significant results and gives them a chance for better quality of life. Preoperative comorbidity could be dealt with, and it should not be considered as a contraindication for surgery in this age group.

Keywords: Degenerative, Lumbar, Elderly, Decompressive laminectomy, Instrumented fusion

\footnotetext{
*Correspondence: arabneuro@gmail.com; ahmed.arab@fmed.bu.edu.eg

Neurosurgery Department, Faculty of Medicine, Benha University, Benha,

Egypt
} 


\section{Background}

With improvement of health care in the last decades, the age of general population increased, and the quality of life for elderly improved. As the elderly population needs to remain physically active for more years, the number and indications of surgeries for degenerative lumbar disease in this age group had increased [1-4]. The surgical risk, low fusion rate, and morbidity are factors that may support decompressive laminectomy and foraminotomy against decompressive surgeries with instrumented fusion in elderly, but some patients after decompression surgery alone may have recurrent axial and/or radicular pain and need fusion later on [4]. Lumbar decompression with instrumented fusion is nowadays gaining wide acceptance in this age group [1-4].

Many studies investigated the clinical and radiological outcomes of lumbar decompression and fusion surgery in elderly including safety, efficacy, life quality after surgery, and perioperative risks and complication and reported that selected elderly population for lumbar decompressive surgery with instrumented fusion benefited a lot from this surgery and had less complications and better life quality [3-8].

The aim of this study is to evaluate the safety and efficacy of open lumbar decompression with instrumented posterolateral fusion in elderly with degenerative lumbar disease not responding to conservative treatment.

\section{Methods}

This is a prospective non randomized clinical study conducted from July 2014 to July 2019. Thirty-five patients were included, and all patients were at least 55 years old at the time of surgery. The patient had chronic low back pain, radiculopathy, and/or neurogenic claudication due to degenerative lumbar disease, with failed conservative treatment.

\section{Preoperative assessment}

Careful assessment of all patients was done starting with history taking including their previous medical status and medical morbidity as DM, HTN, IHD, and other problems, as well as the history and date of last surgery under general anesthesia. Then, history of recent illness was reported regarding low back pain and lower limb problems, as sciatica, neurogenic claudication, and presence or absence of symptoms as muscle weakness (foot drop) and sphincter troubles

General examination and neurologic examination were done for assessment of the back tenderness, lower limb motor power, reflexes, signs of nerve root compression, and gait abnormalities.

When the surgery is decided and patients accepted to have it, routine laboratory tests, electrocardiography (ECG), echocardiography, and chest X-ray were done and revised by the anesthesiologist for surgical fitness. Any medical problem that needed specialized consultation or a period of treatment by other specialties was allowed before considering this patient fit for surgery.

All patients had preoperative MRI lumbosacral spine (LSS) at least 2 months before the surgery, preoperative X-ray LSS views including anteroposterior and lateral, lateral maximum flexion, and extension dynamic views, and right and left oblique. All patients had dual-energy X-ray absorptiometry DEXA before surgery to assess the bone density, and only normal and osteopenic patients were included in this study. Patients with osteopenia had postoperative treatment to improve bone density. Preoperative visual analog score (VAS) and Oswestry disability index (ODI) were evaluated for all patients for further comparison postoperatively.

\section{Surgical procedure}

Briefly, under general anesthesia, patients were operated in prone position. Adequate skin incision was done according to how many level would be approached, followed by muscle separation and preparation for instrumentation. Then, under fluoroscopy, transpedicular screws were inserted, secured, and checked. Laminectomy, facetectomy, and foraminotomy were done to decompress the lumbar canal and foraminae, and in some cases, we did discectomy for disc prolapse compromising the neural structure. After decortication of transverse processes at targeted levels, posterolateral bone autograft was applied to the decorticated surface for fusion. After hemostasis, closure in layers was done and a drain was left and removed within $48 \mathrm{~h}$ after surgery.

Motor power, sensation, sciatica, and wound drain were checked $6 \mathrm{~h}$ postoperatively. Patients were asked for early ambulation; they were closely checked for their comorbidity-if present-and they were discharged usually after 2 to 4 days, but if they had unstable medical or postoperative condition, they were kept until they were stabilized. Wound stitches were removed 2 weeks after surgery and sometimes later in patients with DM. Follow-up visits were done twice monthly for 2 months then at 4, 6, 9, 12, and 18 months, and patients could return in between if needed (Fig. 1).

\section{Postoperative evaluation}

Patients were assessed for VAS and ODI at 18 months after surgery. Postoperative X-ray follow-up was done for all patients at 6 and 18 months. Postoperative MRI was not done regularly but only in case of intolerable persistent pain or signs of discitis and post laminectomy infection.

\section{Statistical analysis}

Software (SPSS, Version 20.0 for Windows, SPSS Inc., Chicago, IL) was used for analysis of the data. 

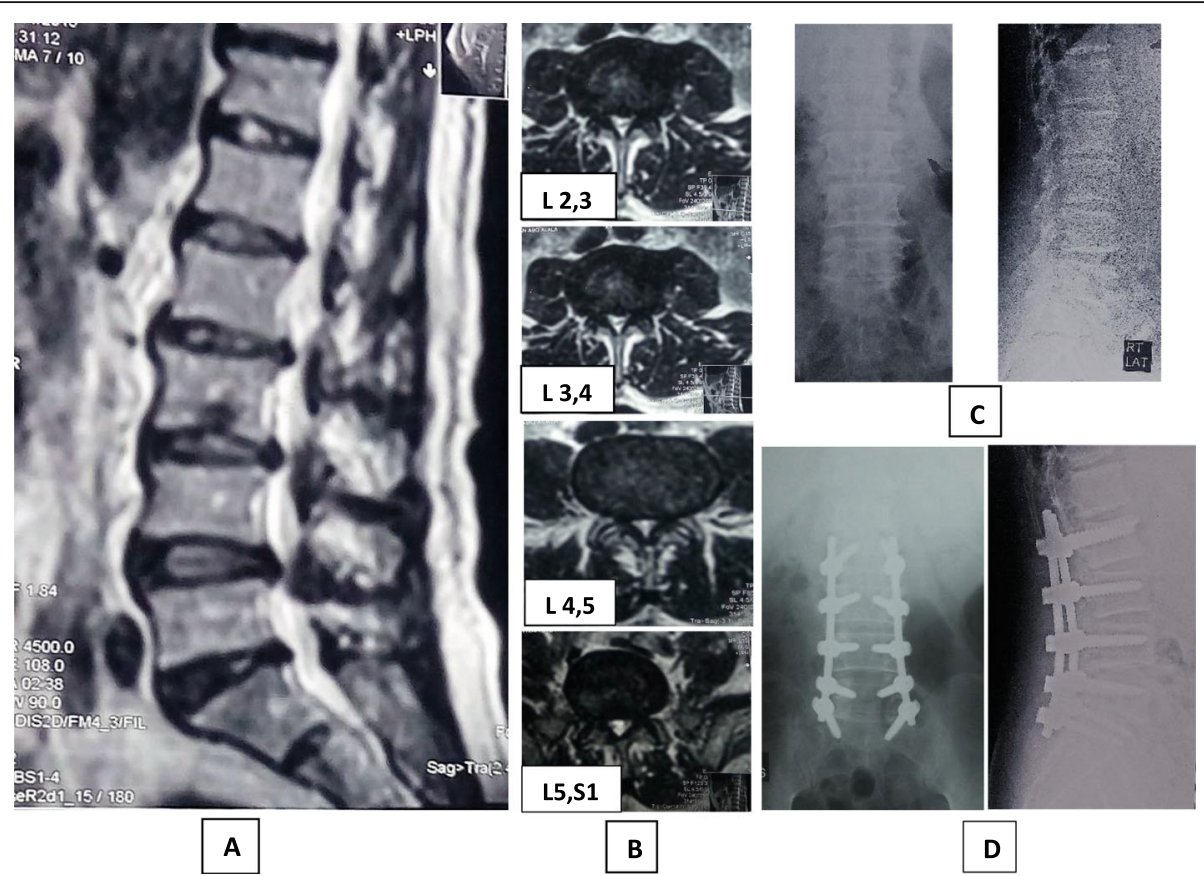

Fig. 1 Seventy-three-year-old male patient, diabetic and had ischemic heart disease presented with low back pain for 3 years that increased in last year, with bilateral lower limb neurogenic claudication and radiculopathy who failed conservative treatment and thus indicated for surgery. He underwent 5 levels of decompression and instrumented fusion. He had no intra- or postoperative complications or disturbed comorbidity. He had improved VAS score from 7 to 1 and ODI from 53 to 6. a, b MRI T2WI sagittal and axial views through L2,3 to L5, S1 showing severe LCS and foraminal stenosis. c Preoperative X-ray, AP and lateral views. d Postoperative X-ray, AP and lateral views

Qualitative variables were summarized as frequency and percentages while quantitative data as mean \pm SD. Wilcoxon (non-parametric) test was applied for the comparison of quantitative variables before and after operation, and a $P$ value $<0.05$ is statistically significant.

\section{Results}

Thirty-five patients were included in this study; 12 patients of them are males (34.3\%), and 23 patients are females (65.7\%); their age ranged from 55 to 79 years (mean age was $63.03 \pm 6.4$ years). The mean duration of symptoms was 21.7, 11.1, and 7.7 months for the low back pain, radiculopathy, and claudication, respectively; low back pain was the main symptom in all cases while $77.1 \%$ had radiculopathy and $60 \%$ had neurogenic claudication (see Tables 1 and 2).

The incidence of preoperative comorbidity was 60\% (21 cases); 15 patients were on antiplatelet $(42.8 \%)$ and they needed special regimen to stop it before and restart it again after surgery, 11 patients were hypertensive (31.4\%), 11 patients were diabetic (31.4\%), 5 patients had

Table 1 Demographic distribution of the patients

\begin{tabular}{lll}
\hline & Range & Mean age \pm SD \\
\hline Age & $55-79$ years & $63.03 \pm 6.4$ years \\
Gender & Males 12 $(34.3 \%)$ & Females 23 $(65.7 \%)$ \\
\hline
\end{tabular}

cardiac ischemic disease (14.3\%), 4 patients had mild hepatic disease (11.4\%), and 2 patients were receiving treatment for hypothyroidism (5.7\%) (see Table 3).

A postoperative new comorbidity occurred in 5 cases; 2 of the diabetic patients $(5.7 \%)$ had poorly controlled $\mathrm{DM}$ at the period of wound healing, 1 patient $(2.8 \%)$ had acute renal insufficiency postoperatively which needed temporary dialysis until his condition was stabilized, 1 patient had asthmatic exacerbation, and 1 patient had temporary hepatic insufficiency (disturbed hepatic function). All of these patients were followed up with related specialty and did well (see Table 4).

Twenty-eight cases $(80 \%)$ had surgery for the first time, and 7 cases $(20 \%)$ had a redo surgery. Some patients were operated for multiple degenerative pathologies. The redo surgeries were for restenosis and inadequate decompression in 4 of 7 cases, spondylolisthesis in 6 of 7 cases, and failed instrumentation in 2 of 7 cases

Table 2 Preoperative clinical presentation

\begin{tabular}{llll}
\hline Symptoms & $\begin{array}{l}\text { Number and } \\
\text { percentage of } \\
\text { patients }\end{array}$ & $\begin{array}{l}\text { Duration of } \\
\text { symptoms (Range } \\
\text { in months) }\end{array}$ & $\begin{array}{l}\text { Duration of } \\
\text { symptoms } \\
\text { (mean } \pm \text { SD) }\end{array}$ \\
\hline LBP & $35(100 \%)$ & $3-36 \mathrm{~m}$ & $21.7 \pm 11.1 \mathrm{~m}$ \\
Radiculopathy & $27(77.1 \%)$ & $1-30 \mathrm{~m}$ & $11.1 \pm 7.9 \mathrm{~m}$ \\
$\begin{array}{l}\text { Neurogenic } \\
\text { laudication }\end{array}$ & $21(60 \%)$ & $1-24 \mathrm{~m}$ & $7.7 \pm 5.2 \mathrm{~m}$ \\
\hline
\end{tabular}


Table 3 Preoperative comorbidity

\begin{tabular}{lll}
\hline Preoperative comorbidity & Number & $\%$ \\
\hline Cardiac (mainly IHD) & 5 & $14.3 \%$ \\
HTN & 11 & $31.4 \%$ \\
Respiratory & 0 & $0 \%$ \\
DM & 11 & $31.4 \%$ \\
Renal insufficiency & 0 & $0 \%$ \\
Hepatic disease & 4 & $11.4 \%$ \\
On Antiplatelet & 15 & $42.8 \%$ \\
Smoker & 4 & $11.4 \%$ \\
Hypothyroidism on treatment & 2 & $5.7 \%$ \\
\hline
\end{tabular}

(see Table 5). Nine patients had 2 levels of instrumented fusion, 19 cases had 3 levels, 3 cases had 4 levels, and 4 cases had 5 levels, with a total of 107 levels done and a mean of 3.1 levels.

We had 2 cases (5.7\%) with intraoperative dural tear; we did primary repair in both cases, where one of them had postoperative CSF leak that needed revision, and we had another case of CSF leak that we discovered postoperatively and was treated conservatively. We had 1 case $(2.8 \%)$ with subcutaneous wound seroma and another case of wound infection; antibiotics were given for 4 weeks, and the patient did well (see Table 6).

All included patients had completed at least a period of 18 months of follow-up, and they were reevaluated for VAS and ODI at 18 months. There was a significant improvement in VAS from $7.8 \pm 0.87$ to $1.8 \pm 1.04$ with $P$ value $<0.00001$ and in ODI from $58.1 \pm 11$ to17.5 \pm 8.3with $P$ value $<0.00001$ (see Table 7).

\section{Discussion}

Degenerative lumbar spine disease is a common and major cause of morbidity and disturbed social life in elderly [9]; regular daily activity of this age category is severely affected by back pain and lower limb pain resulting from mechanical back problems and nerve root compression [10]. Usually, conservative treatment is favored especially in elderly population with comorbidity, but non-responsive patients require surgical treatment [11].

In patients with degenerative spine disease, anatomical degenerative changes usually require wide decompression with partial or complete facetectomy to free the

Table 4 Postoperative comorbidity

\begin{tabular}{lll}
\hline Postoperative comorbidity & Number & $\%$ \\
\hline DM & 2 & $5.7 \%$ \\
Respiratory disease & 1 & $2.8 \%$ \\
Renal insufficiency & 1 & $2.8 \%$ \\
Hepatic disease & 1 & $2.8 \%$ \\
\hline
\end{tabular}

Table 5 Indication for surgery

\begin{tabular}{|c|c|c|c|c|}
\hline $\begin{array}{l}\text { Type of surgery } \\
\text { (Number and \%) }\end{array}$ & $\begin{array}{l}\text { Indication for } \\
\text { surgery }\end{array}$ & Number & $\begin{array}{l}\% \text { of } \\
\text { patients to } \\
\text { category } \\
\text { (Primary or } \\
\text { Redo) }\end{array}$ & $\begin{array}{l}\% \text { of } \\
\text { patients } \\
\text { to all } \\
\text { cases }\end{array}$ \\
\hline \multirow[t]{3}{*}{$\begin{array}{l}\text { Primary surgery ( } 28 \text { cases } \\
80 \%)\end{array}$} & $\begin{array}{l}\text { Lumbar canal and } \\
\text { foraminal stenosis }\end{array}$ & $21 / 28$ & $75 \%$ & $60 \%$ \\
\hline & Spondylolisthesis & $26 / 28$ & $92.9 \%$ & $74.3 \%$ \\
\hline & $\begin{array}{l}\text { Lumbar disc } \\
\text { prolapse }\end{array}$ & $5 / 28$ & $17.9 \%$ & $14.3 \%$ \\
\hline \multirow[t]{3}{*}{$\begin{array}{l}\text { Redo surgery ( } 7 \text { cases } \\
20 \%)\end{array}$} & $\begin{array}{l}\text { Restenosis and /or } \\
\text { inadequate } \\
\text { decompression }\end{array}$ & $4 / 7$ & $57.1 \%$ & $11.4 \%$ \\
\hline & Spondylolisthesis & $6 / 7$ & $85.7 \%$ & $17.1 \%$ \\
\hline & $\begin{array}{l}\text { Failed } \\
\text { instrumentation }\end{array}$ & $2 / 7$ & $28.6 \%$ & $5.7 \%$ \\
\hline
\end{tabular}

neural tissue, but iatrogenic instability may occur and results in mechanical back pain and secondary neural compromise [12]. This is besides the patients which present mobile spondylolisthesis. Instrumented fusion is indicated in such patient to treat mechanical instability and to avoid effects of iatrogenic instability besides achieving good graft integration $[12,13]$.

From the review of the literature, we found that different opinions were discussed about safety and efficacy of lumbar decompression and instrumented fusion for treatment of degenerative lumbar diseases in the elderly; the neurosurgeons operating on elderly patients should be aware of perioperative problems in this advanced age and have to discuss with them the increased surgical risks as well as the benefits from surgical treatment of their spine disease [14]. Older reports had stated that discectomy and also other lumbar procedures in the elderly had shown an increased rate of morbidity and mortality $[15,16]$. These reports are 30 years ago and older since that a lot of advances in health care were established specially for the elderly. In the last two decades, increasing age is not considered a contraindication for spine surgery, and so the rate of spine surgical procedures is increasing dramatically $[13,17]$.

Surgery is done on an elective basis, so there is always a chance to review patients' health status and optimize their medical condition prior to surgery, but sometimes, surgery can be delayed until proper preparation is done when the perioperative risk is perceived to be high.

Table 6 Operative and postoperative complications

\begin{tabular}{llll}
\hline Operative and postoperative complications & Number & $\%$ \\
\hline Dural tear (intraoperative) & & 2 & $5.7 \%$ \\
Wound findings & Seroma & 1 & $2.8 \%$ \\
& CSF leakage & 2 & $5.7 \%$ \\
& Infection & 1 & $2.8 \%$ \\
\hline
\end{tabular}


Table 7 Preoperative and 18 months postoperative VAS and ODI

\begin{tabular}{lllll}
\hline Evaluation scale & Preoperative & $\mathbf{1 8}$ months postop. & Wilcoxon test & $P$-value \\
\hline VAS $($ Mean \pm SD) & $7.8 \pm 0.87$ & $1.8 \pm 1.04$ & -5.159 & $<0.00001^{*}$ \\
ODI $($ Mean $\pm S D)$ & $58.1 \pm 11$ & $17.5 \pm 8.3$ & -5.159 & $<0.00001^{*}$
\end{tabular}

VAS Visual analog scale, ODI Oswestry disability index. ${ }^{*} P$ value

Prognostication of risk is usually imperfect and subjective incorporating the input of anesthesiologist, surgeon, and other managing physicians [7].

The average life expectancy in Egypt is 72.5 years; this is low in comparison to most Western and some Asian countries (79 to 85.3 years), and it gives an idea about the general health care and relative lack of proper management of elderly health problems (Worldometer.info). Besides, most of our patients in this study were heavy workers, including the females that had to work to manage their life needs, so they had earlier degenerative lumbar changes. For this purpose, we studied an age group which ranged from 55 to 79 years that is younger than what was studied in other research works, but we thought it should be more representable of our people average life expectancy and serving our goal of the study.

Perioperative complications are related to increased intraoperative blood loss operative time and also adding instrumentation and fusion to decompression [14, 18]. In this study's surgeries, we utilized our experience in spine surgery, spinal instrumentation, and fusion in order to decrease operative time and blood loss, and so, intraoperative or postoperative blood transfusion was given when needed, and this occurred in 5 of our patients. The anesthesiologist offered great care and attention for our patients to avoid perioperative problems.

The orthopedic surgeons usually consider total hip arthroplasty as a regular surgery in elderly people. In a study that compared total hip arthroplasty to lumbar spine decompression and fusion, there was no significant difference in perioperative risks, comorbidity, and complications. They stated that increasing age should not be considered as a contraindication for surgery, and proper selection and preparation can lead to satisfactory improvement [19, 20].

In this study, we had a VAS \pm SD score of $7.8 \pm 0.87$ preoperatively which improved to $1.8 \pm 1.04$, and ODI \pm SD score improved also from $57.7 \pm 11.01$ to $11.8 \pm 6.9$; these improvements are found statistically significant and were in line with other studies done on quite similar sample of patients $[6,14,21-23]$. Also, in this study, 6 patients with ODI postoperative score $>20$ had good improvement in comparison to their previous condition, but the results were not satisfactory for them.

Reasonably, adding instrumented fusion to decompression may increase perioperative complication especially in elderly $[14,15]$, and it may be wise not to consider this, but many patients may have considerable back pain that will not be relieved with decompression only, so, we have to consider to weight out risk versus benefit towards decompression with instrumented fusion as it is safe and justifiable [4]. Patients presented with mechanical back pain or expected to have it after decompression will benefit from instrumented fusion, and also, they will have an added procedure that they may need in the future. It is not better to have a redo surgery for fusion after open decompression as it will be risky and lengthy. Lee et al. worked on 50 cases and suggested that patients with back pain as a main complain are needed to be considered as a surgical candidate for fusion and instrumentation [4].

\section{Conclusion}

Lumbar decompression with instrumented posterolateral fusion is a safe and effective surgery in elderly, and it gives them a chance for better quality of life. Preoperative comorbidity could be dealt with, and it should not be considered as a contraindication for surgery in this age group.

\section{Abbreviations}

DM: Diabetes mellitus; HTN: Hypertension; IHD: Ischemic heart disease; MRI: Magnetic resonance image; CSF: Cerebrospinal fluid; DEXA: Dual-energy X-ray absorptiometry; VAS: Visual analog score; ODI: Oswestry disability index

\section{Acknowledgements}

The authors thank all included patients.

\section{Authors' contributions}

$A A, M E$, and $A E$ performed the clinical part of the study. AA and $A E$ analyzed the data, wrote the paper, and did the revision. All authors have read and approved the manuscript.

\section{Funding}

This study had no funding from any resource.

\section{Availability of data and materials}

Data supporting our finding is available from the corresponding author (you can contact on email), and we do not wish to share this data except on demand after contacting the corresponding author.

\section{Declarations}

Consent to participate

All participants had signed consent to participate.

\section{Ethics approval and consent to participate}

This observational study was given approval by the Research Ethics Committee (REC) of Neurosurgery Department, Benha Faculty of Medicine, Benha University, on 12 March 2017 (the reference number is not applicable). A written informed consent was obtained from each patient after explaining all the steps of this study. All procedures performed involving human participants were in accordance with the ethical standards 
of the institutional and/or national research committee and with the 1964 Helsinki declaration and its later amendments or comparable ethical standards.

\section{Competing interests}

The authors declare that they have no conflict of interest.

Received: 16 June 2020 Accepted: 18 April 2021

Published online: 29 April 2021

\section{References}

1. Yone K, Sakou T, Kawauchi Y, et al. Indication of fusion for lumbar spinal stenosis in elderly patients and its significance. Spine. 1996;21(2):242-8. https://doi.org/10.1097/00007632-199601150-00016.

2. Kilincer C, Steinmetz MP, Sohn MJ, et al. Effects of age on the perioperative characteristics and short-term outcome of posterior lumbar fusion surgery. J Neurosurg Spine. 2005;3(1):34-9. https://doi.org/10.3171/spi.2005.3.1.0034.

3. Cavagna R, Tournier C, Aunoble S, Bouler JM, Antonietti P, Ronai M, et al. Lumbar decompression and fusion in elderly osteoporotic patients: a prospective study using less rigid titanium rod fixation. J Spinal Disord Tech. 2008;21(2):86-91. https://doi.org/10.1097/BSD.0b013e3180590c23.

4. Lee C-H, Hyun S-J, Kim K-J, Jahng T-A, Kim H-J. Decompression only versus fusion surgery for lumbar stenosis in elderly patients over 75 years old: which is reasonable? Neurol Med Chir (Tokyo). 2013;53(12):870-4. https:// doi.org/10.2176/nmc.oa2012-0415.

5. Cloyd JM, Acosta FL, Ames CP. Complications and outcomes of lumbar spine surgery in elderly people: a review of the literature. JAGS. 2008;56(5): 1318-27. https://doi.org/10.1111/j.1532-5415.2008.01771.x.

6. Costa F, Ortolina A, Tomei M, Cardia A, Zekay E, Fornari M. Instrumented fusion surgery in elderly patients (over 75 years old): clinical and radiological results in a series of 53 patients. Nov. 2013;22(Suppl 6):910-3.

7. Wang MY, Widi G. Levi AD (2015) The safety profile of lumbar spinal surgery in elderly patients 85 years and older. Neurosurg Focus. 2015;39(4):E3. https://doi.org/10.3171/2015.7.FOCUS15180.

8. Bouloussa H, Alzakri A, Ghailane S, Vergari C, Mazas S, Vital JM, et al. Is it safe to perform lumbar spine surgery on patients over eighty five? Int Orthop. 2017;41(10):2091-6. https://doi.org/10.1007/s00264-017-3555-6.

9. Yong-Hing K, Kirkaldy-Willis WH. The pathophysiology of degenerative disease of the lumbar spine. Orthop Clin North Am. 1983;14(3):491-504. https://doi.org/10.1016/S0030-5898(20)31329-8.

10. Jonsson B, Stromqvist B. Symptoms and signs of degeneration of the lumbar spine: a prospective, consecutive study of 300 operated patients. J Bone Joint Surg (Br). 1993;75(3):381-5. https://doi.org/10.1302/0301-620X. 75B3.8496204.

11. Tadokoro K, Miyamoto H, Sumi M, Shimomura T. The prognosis of conservative treatments for lumbar spinal stenosis: analysis of patients over 70 years of age. Spine. 2005;30(21):2458-63. https://doi.org/10.1097/01.brs. 0000184692.71897.a2.

12. Fischgrund JS, Mackay M, Herkowitz HN, Brower R, Montgomery DM, Kurz LT. Degenerative lumbar spondylolisthesis with spinal stenosis: a prospective randomized study comparing decompressive laminectomy and arthrodesis with and without spinal instrumentation. Spine. 1997;22(24): 2807-12. https://doi.org/10.1097/00007632-199712150-00003.

13. Piñera AR, Duran C, Lopez B, Saez I, Correia E, Alvarez L. Instrumented lumbar arthrodesis in elderly patients: prospective study using cannulated cemented pedicle screw instrumentation. Eur Spine J. 2011;20(Suppl 3):40814.

14. Carreon LY, Puno RM, Dimar JR 2nd, Glassman SD, Johnson JR. Perioperative complications of posterior lumbar decompression and arthrodesis in older adults. J Bone Joint Surg Am. 2003;85-A(11):2089-92.

15. Deyo RA, Ciol MA, Cherkin DC, Loeser JD, Bigos SJ. Lumbar spinal fusion. A cohort study of complications, reoperations, and resource use in the Medicare population. Spine. 1993;18(11):1463-70. https://doi.org/10.1097/ 00007632-199318110-00010.

16. Deyo RA, Cherkin DC, Loeser JD, Bigos SJ, Ciol MA. Morbidity and mortality in association with operations on the lumbar spine. The influence of age, diagnosis, and procedure. J Bone Joint Surg Am. 1992;74(4):536-43. https:// doi.org/10.2106/00004623-199274040-00009.

17. Shabat S, Arinzon Z, Folman Y, et al. Long-term outcome of decompressive surgery for lumbar spinal stenosis in octogenarians. Eur Spine J. 2008;17: 193-8.
18. Benz RJ, Ibrahim ZG, Afshar P, Garfin SR. Predicting complications in elderly patients undergoing lumbar decompression. Clin Orthop Relat Res. 2001; 384:116-21. https://doi.org/10.1097/00003086-200103000-00014.

19. Reindl $R$, Steffen $T$, Cohen $L$, et al. Elective lumbar spinal decompression in the elderly: is it a high-risk operation? Can J Surg. 2003;46:43-6.

20. Jakola AS, Sørlie A, Gulati S, Nygaard ØP, Lydersen S, Solberg T. Clinical outcomes and safety assessment in elderly patients undergoing decompressive laminectomy for lumbar spinal stenosis: a prospective study. BMC Surg. 2010;10(1):34. https://doi.org/10.1186/1471-2482-10-34.

21. Glassman SD, Carreon LY, Dimar JR, Campbell MJ, Puno RM, Johnson JR. Clinical outcomes in older patients after posterolateral lumbar fusion. Spine J. 2007;7(5):547-51. https://doi.org/10.1016/j.spinee.2006.11.003.

22. Endres S. Instrumented posterolateral fusion, clinical and functional outcome in elderly patients. Ger Med Sci. 2011;9:Doc09.

23. Andersen T, Christensen FB, Niedermann B, Helmig P, Høy K, Hansen ES, et al. Impact of instrumentation in lumbar spinal fusion in elderly patients: 71 patients followed for 2-7 years. Acta Orthop. 2009;80(4):445-50. https:// doi.org/10.3109/17453670903170505.

\section{Publisher's Note}

Springer Nature remains neutral with regard to jurisdictional claims in published maps and institutional affiliations.

\section{Submit your manuscript to a SpringerOpen ${ }^{\circ}$ journal and benefit from:}

- Convenient online submission

- Rigorous peer review

- Open access: articles freely available online

- High visibility within the field

- Retaining the copyright to your article

Submit your next manuscript at $\boldsymbol{\sim}$ springeropen.com 